\title{
Ubiquitous Usage of Over the Counter Medications in Pregnancy: Perspectives of Maternal Apprehensiveness
}

\author{
Gudisa Bereda \\ Department of Pharmacy, Negelle Health Science College, Guji, Ethiopia
}

Corresponding Author: Gudisa Bereda, Department of Pharmacy, Department of Pharmacy, Negelle Health Science College, Guji, Ethiopia

Received date: November 22, 2021; Accepted date: December 29, 2021; Published date: January 06, 2021

Citation: Gudisa Bereda (2022). Ubiquitous Usage of Over the Counter Medications in Pregnancy: Perspectives of Maternal Apprehensiveness. J. Women Health Care and Issues. 5(1); DOI:10.31579/2642-9756/097

Copyright: (c) 2022 Gudisa Bereda, This is an open access article distributed under the Creative Commons Attribution License, which permits unrestricted use, distribution, and reproduction in any medium, provided the original work is properly cited.

\begin{abstract}
The World Health Organization delineates self-medication as the utilization of medications by individuals in search of treating symptoms or self-diagnosed health state. During pregnancy, drug utilization is complicated because of incomplete data as clinical trials frequently don't enclose pregnant women, with reference to benefits and implicit undesirable outcomes on both the mother and the foetus. Bestowed limited data on the variety of over the counter medications applicable, physicians seek to counsel pregnant women about implicit pitfalls, and it is beneficial to give information on entire over the counter medications the patient is receiving at the preconception visit and entire distinctive ordinary visits. Antacid that containing sodium bicarbonate can cause fluid buildup in the tissues if used during pregnancy redundantly. Hypericum perforatum is ordinarily not recommended in pregnancy because of a dearth of human data and it perhaps antecedent miscarriage and it also escalates the birth deformities of fetus. Early aspirin usage at the time of conception or in the $1^{\text {st }}$ several weeks of pregnancy does not escalate the pitfall of spontaneous abortion.
\end{abstract}

Keywords: over the counter; medications; pregnancy; ubiquitous; usage

\section{Introduction}

Pregnancy care imposes a consummate challenge to both the health care furnishers and pregnant women because drug utilization during pregnancy perhaps negatively influences the lives of the mothers and the growing fetus. Medication usage during pregnancy has consistently created a challenge in antenatal care owing to the potential foetal peril consociated with the use. Drug utilization studies display that consummate women use medications during pregnancy with estimations varying from $44 \%$ to $99 \%$ [1]. The WHO delineates self-medication as the utilisation of medications by individuals in search of treating symptoms or self-diagnosed health state [2]. OTC medication is taken by over $90 \%$ of pregnant women [3]. Although OTC medications have attested to be efficient and secure and are intended for self-medication, but wrong usage or abuse suggest serious consequences, particularly in geriatrics, pediatrics, pregnant and lactating women $[4,5]$. Pregnancy is a special bodily processing state where medication uptake is a considerable concern and presents a remonstrance as revamped medication pharmacokinetics and medication crossing the placenta perhaps causes detriment to the foetus [6]. In pregnant women, self-medication is narrated to be ubiquitous because of a variety of complaints affiliated to pregnancy, like back pain, headache, nausea, vomiting, heartburn and haemorrhoids $[7,8]$. During pregnancy, drug utilization is complicated because of incomplete data as clinical trials frequently don't enclose pregnant women, with reference to benefits and implicit undesirable outcomes on both the mother and the foetus [9]. Pregnant women are ordinarily excluded from medical trials and sequences from animal studies seek not apply to human population. Consequently treating pregnant women with certain medications is a terrible and consummate clinicians have a rather bounded approach to the usage of medications during pregnancy. Fear of causing fetal affliction and death through medication usage in pregnancy has sequenced in multiplex challenges to clinical research about the safety of medications in pregnancy. Thereupon medication safety information in pregnancy is frankly acquired through case reports, epidemiological studies and animal studies; entire of which have limitations, which make determining pitfalls of a medication usage during pregnancy difficult [10]. Medications that a pregnant woman takes can influence the fetus in several ways. They can act directly on the fetus causing detriment or abnormal development leading to birth anomalies or death. They can also revamp the work of the placenta ordinarily by constricting blood vessels and downgrading the blood supply of oxygen and nutrients to the fetus from the mother and thus sequencing in a baby that is underweight and underdeveloped. Furthermore they can cause the muscles of the uterus to contract forcefully; indirectly damaging the fetus by de-escalating the blood supply or triggering pre-term labor and delivery [11]. Whereas there are no randomized controlled trials to mentor 
the usage of OTC medications during pregnancy, women frequently use them for skin, allergy, respiratory, and gastrointestinal circumstances in addition to general analgesia. Entire physicians caring for reproductiveaged women should be familiar with the indications, perils, and benefits of OTC medications in pregnancy. Bestowed limited data on the variety of OTC medications applicable, physicians seek to counsel pregnant women about implicit pitfalls, and it is beneficial to give information on entire OTC medications the patient is receiving at the preconception visit and entire distinctive ordinary visits [12]. Ubiquitously used medications during pregnancy consummately were narrated beneath: During pregnancy heartburn happens in up to $80 \%$ of pregnant women by the end of the $3^{\text {rd }}$ trimester. Antacids containing aluminum, calcium, or magnesium are frequently thought-out $1^{\text {st }}$-line treatment in pregnancy. Nevertheless, at high doses, antacids containing calcium can cause milkalkali syndrome and interferes with contractions during labor [13] and antacids with aluminum can cause neurotoxicity. Antacid that containing $\mathrm{NaHCO}_{3}$ can cause fluid buildup in the tissues if used during pregnancy redundantly. Selective histamine $\mathrm{H}_{2}$ blockers have been used in entire trimesters with no known teratogenic effects; $\mathrm{H}_{2}$ blocker medications, such as famotidine, cimetidine, and ranitidine, attested in the United States for acid reflux, pose no significant perils for the fetus [14]. Proton pump inhibitors nowadays became attainable OTC. Entire PPIs medications are USFDA, classifications category B, which delineated as entire of them are secure during pregnancy, because there is no concrete evidence that they cause miscarriage, stillbirth, preterm, delivery, birth deformities, and low infant birth weight. Proton pump inhibitors and $\mathrm{H}_{2}$ blockers are thought-out secure in pregnancy [15]. Topical steroid creams perhaps dysregulated placental hormones and likely obviate indispensable proteins from getting to the baby, and women used the ointments were also more probably to have asthma and to receive other high peril medications during pregnancy than those who didn't. Usage of topical retinol such as skin cream is not consociated with perils on fetus deformities. Topical antifungals are ubiquitously used during pregnancy for treatment of vulvovaginitis. Imidazoles and nystatin is well studied and thought-out secure during pregnancy. Nystatin is minimally absorbed and is effective for vaginal therapy [16-18]. During pregnancy, herbal remedies are used for nausea, respiratory symptoms, urinary tract infections, pain, and disparate nonspecific issues. Using herbal medicine in $1^{\text {st }} 3$ months and late in $3^{\text {rd }}$ trimester is detrimental for the fetus. The ubiquitous detrimental effects of using herbal remedies in pregnancy are heart burn; escalate blood flow, premature labor, miscarriage, allergic reactions and abortion. Distinctive survey's displayed that using herbal remedies during the $1^{\text {st }} 12$ weeks and the last 12 weeks of gestation is detrimental for the fetus [19]. Hypericum perforatum is ordinarily not recommended in pregnancy because of a dearth of human data and it perhaps antecedent miscarriage and it also escalates the birth deformities of fetus [20, 21]. Dextromethorphan is a nonnarcotic antitussive isomer of codeine that was found to be teratogenic in chicken embryos. Nevertheless, a human epidemiologic study and a smaller controlled study did not demonstrate escalated perils of congenital malformations, but it perhaps negatively affect the pregnant women and her fetus if overused or misused [22]. Up to $15 \%$ of women usage an antihistamine during pregnancy to treat allergic rhinitis or nausea [23]. Studies continually reveal no significant pitfall of fetal malformations with $1^{\text {st }}$ generation antihistamines, and these agents are thought-out secure and certain $2^{\text {nd }}$ generation antihistamines usage perhaps consociated with pregnancy outcomes such as spontaneous abortion and preterm birth. Preponderance of antihistamine medications are USFDA category $\mathrm{C}$, solely a few antihistamines are category B delineated as either animalreproduction inquests have not substantiated a fetal peril but there are no restrained inquests in pregnant women or animal-reproduction inquests have reveal an adverse effect (other than a de-escalate in fertility) that was not inveterate in restrained inquests in women in the first trimester (and there is no confirmation of a pitfall in later trimesters) or there is survey in animal that revealed the medication is safe in pregnant animal, but there is no fetal pitfall confirmation in pregnant women. Medications in this class are typically thought-out secure. Recently there are no safety guidelines for the usage of antihistamines during pregnancy [24-26]. Early aspirin usage at the time of conception or in the $1^{\text {st }}$ several weeks of pregnancy does not escalate the pitfall of spontaneous abortion [27]. Suppression of prostaglandin synthesis perhaps harmfully affects the pregnancy and/or the embryo/foetal [28]. During the $1^{\text {st }}$ and $2^{\text {nd }}$ trimester of pregnancy, ASA should not be bestowed [29]. During the $3^{\text {rd }}$ trimester of pregnancy, entire prostaglandin generation inhibitors perhaps expose the foetus to antecedent cardiopulmonary toxicity (with premature closure of the ductus arteriosus and pulmonary hypertension); renal dysfunction, which perhaps advances to renal failure with oligohydraminosis [30]. Prostaglandin synthesis inhibitors perhaps expose both the mother and the child at the end of pregnancy to: attainable prolongation of bleeding time/escalated INR, an anti-aggregating outcome which perhaps happen even after very low doses; suppression of uterine contractions sequencing in holding pattern or extended labour or ASA is pregnancy category C (pitfall can't be ruled out) signifies either inquests in animals have displayed adverse effects on the fetus (teratogenic or embryocidal, or other) and there are no restrained inquests in women or inquests in women and animals are not avail. Drugs should be accustomed only if the implicit advantage maintains the implicit peril to the fetus or the survey in animal model displayed slight pitfall to the pregnant animal, but there is no confirmation in fetal peril of human survey in pregnant women [31]. Collectedly, ASA should be avoided during organogenesis and in the $3^{\text {rd }}$ trimester unless a physician particularly prescribes it and the patient understands the pitfalls and benefits NSAIDs are not recommended in the $3^{\text {rd }}$ trimester because of the peril of premature closure of the ductus arteriosus and subsequent initial pulmonary hypertension in the newborn [32]. The National Birth Defects Prevention Study, which analyzed data from 16,110 children in the United States exposed to acetaminophen in utero, found no escalated perils of birth anomalies with acetaminophen use. In pregnant women using acetaminophen particularly for febrile illness, there were de-escalated pitfalls of various cranial and facial deformities and gastroschisis, acetaminophen perhaps protective because fever heightens the peril of these deformities [33]. Acetaminophen is sole of the consummate broadly used medications in pregnancy and is ordinarily thought-out secure [34]. Unfortunately, acetaminophen is also among the consummate ubiquitously narrated agents implicated in overdoses during pregnancy [35]. High quanta of data on pregnant women indicate neither malformative, nor feto/neonatal toxicity. Epidemiological surveys on neurodevelopment in children exposed to paracetamol in utero reveal inconclusive sequences [36, 37]. Paracetamol-caffeine is not recommended for use during pregnancy owing to the probable escalated peril of spontaneous abortion consociated with caffeine devour [38, 39]

\section{Conclusion}

In pregnant women, self-medication is narrated to be ubiquitous because of a variety of complaints affiliated to pregnancy, like back pain, headache, nausea, vomiting, heartburn and haemorrhoids. Medications that a pregnant woman receives can influence the fetus in several ways. They can act directly on the fetus causing detriment or abnormal development leading to birth anomalies or death. OTC medication is taken by over $90 \%$ of pregnant women. Entire PPIs medications are USFDA, classifications category B, which delineated as entire of them are secure during pregnancy, because there is no concrete evidence that the cause miscarriage, stillbirth, preterm, delivery, birth deformities, and low infant birth weight. Topical steroid creams perhaps dysregulated placental hormones and likely obviate indispensable proteins from getting to the baby, and women used the ointments were also more probably to have asthma and to receive other high peril medications during pregnancy than those who didn't. 


\section{Abbreviations}

ASA: Aspirin; INR: International normalized ratio; $\mathrm{NaHCO}_{3}$ : Sodium bicarbonate; OTC: Over the counter; PPI: Proton pump inhibitors; USFDA: United States food and drug administration; WHO: World health organization

Data Sources: Sources searched include Google Scholar, Research Gate, PubMed, NCBI, NDSS, PMID, PMCID, and Cochrane database. Search terms included: over the counter medications used during pregnancy.

\section{Acknowledgments}

The author acknowledg

ed Endnote-8, Google scholar, Medscape, Wikipedia, and PubMed.

\section{Conflicts of interest}

The author declared that they have no competing interest

\section{Funding}

None

\section{Declarations}

\section{Ethical approval and consent to participate}

Not applicable

\section{Consent for publication}

Not applicable

\section{Availability of data and materials}

The datasets generated during the current study are available with correspondent author.

\section{Competing interests}

The author has no financial or proprietary interest in any of material discussed in this article.

\section{Author's contributions}

GB contributed to preparing the first draft, review and editing the draft, and finally read and approved the manuscript.

\section{References}

1. Bereda G, Bereda G. Drug usage pattern and potential teratogenesity risk among pregnant women attending maternal and child health clinic of Mettu Karl Referral Hospital, South Western, Ethiopia: a cross sectional study, 2021. Int J Pregn \& Chi Birth. 2021; 7(4):83-90. DOI: 10.15406/ipcb.2021.07.00234.

2. World Health Organization: Role of pharmacists in self-care and self-medication.[online] [Cited 2015 may 16]. Available from:

3. Mitchell AA, Gilboa SM,Werler MM, Kelley KE, Louik C, Hernández-Díaz S; National Birth Defects Prevention Study. Medication use during pregnancy, with particular focus on prescription drugs:1976-2008. Am J Obstet Gynecol 2011; 205: 51.e1-8

4. Murray MD, Callahan CM. Improving Medication Use for Older Adults: An Integrated Research Agenda. Ann Int Med 2003; 139: 2425-2459.

5. Choonara I, Gill A, Nunn A. Drug Toxicity and Surveillance in children. Br J Clin Pharm 1996; 42: 407-410.

6. Banhidy F, Lowry RB, Czeizel AE. Risk and benefit of drug use during pregnancy. Int J Med Sci 2005; 2: 100-106.

7. Gibson PS, Powrie R, Star J. Herbal and alternative medicine use during pregnancy: a cross-sectional survey. Obstet Gynecol 2001; 97: S44-S45.
8. Pangle BL. Drugs in pregnancy and lactation. In: Herfindal ET, Gourley DR, editor . Textbook of therapeutics, drug and disease management. 8th ed. Philadelphia: Lippincott William Wilkins; 2006.

9. Stephansson O, Granath F, Svensson T, Haglund B, EkbomA, Kieler H. Drug use during pregnancy in Sweden - assessed by the Prescribed Drug Register and the Medical Birth Register. Clin Epidemiol 2011; 3: 43-50.

10. Ward RW. Difficulties in the study of adverse fetal and neonatal effects of drug therapy during pregnancy. Semin Perinatol 2001;25:191-195.

11. Loebstein R, Lalkin A, Koren G. Pharmacokinetic changes during pregnancy and their clinical relevance. Clin Pharmacokinet1997;33:328-343.

12. Mitchell AA, Gilboa SM, Werler MM, Kelley KE, Louik C, Hernández- Díaz S; National Birth Defects Prevention Study. Medication use during pregnancy, with particular focus on prescription drugs: 1976-2008. Am J Obstet Gynecol. 2011;205(1):51.e1-51.e8.

13. Law R, Maltepe C, Bozzo P, Einarson A. Treatment of heartburn and acid reflux associated with nausea and vomiting during pregnancy. Can Fam Physician. 2010;56(2):143-144.

14. Murase JE, Heller MM, Butler DC. Safety of dermatologic medications in pregnancy and lactation: Part I. Pregnancy. J Am Acad Dermatol. 2014; 70(3):401.e1-14.

15. Pasternak B, Hviid A. Use of proton-pump inhibitors in early pregnancy and the risk of birth defects. $N$ Engl $J$ Med. 2010;363(22):2114-2123.

16. Pursley TJ, Blomquist IK, Abraham J, Andersen HF, Bartley JA. Fluconazole-induced congenital anomalies in three infants. Clin Infect Dis. 1996;22(2):336-340.

17. Nørgaard M, Pedersen L, Gislum M, et al. Maternal use of fluconazole and risk of congenital malformations: a Danish population-based cohort study. $J$ Antimicrob Chemother. 2008;62(1):172-176.

18. King CT, Rogers PD, Cleary JD, Chapman SW. Antifungal therapy during pregnancy. Clin Infect Dis. 1998;27(5):1151-1160.

19. Broussard CS, Louik C, Honein MA, Mitchell AA; National Birth Defects Prevention Study. Herbal use before and during pregnancy. Am J Obstet Gynecol. 2010;202(5):443.e1-443.e6.

20. U.S. Food and Drug Administration. Dietary supplements. Accessed July 30, 2013.

21. Conover EA. Over-the-counter products: nonprescription medications, nutraceuticals, and herbal agents. Clin Obstet Gynecol. 2002;45(1): 89-98.

22. Einarson A, Lyszkiewicz D, Koren G. The safety of dextromethorphan in pregnancy: results of a controlled study. Chest. 2001;119(2):466-469.

23. Gilbert C, Mazzotta P, Loebstein R, Koren G. Fetal safety of drugs used in the treatment of allergic rhinitis: a critical review. Drug Saf. 2005; 28(8):707-719.

24. Schatz M, Zeiger RS, Harden K, Hoffman CC, Chilingar L, Petitti D. The safety of asthma and allergy medications during pregnancy. J Allergy Clin Immunol. 1997;100(3):301-306.

25. Seto A, Einarson T, Koren G. Pregnancy outcome following first trimester exposure to antihistamines: meta-analysis. Am J Perinatol. 1997; 14(3):119-124.

26. Gilboa SM, Strickland MJ, Olshan AF, Werler MM, Correa A National Birth Defects Prevention Study. Use of antihistamine medications during early pregnancy and isolated major malformations. Birth Defects Res A Clin Mol Teratol. 2009;85(2):137-150.

27. Edwards DR, Aldridge T, Baird DD, Funk MJ, Savitz DA, Hartmann KE. Periconceptional over-the-counter nonsteroidal 
anti-inflammatory drug exposure and risk for spontaneous abortion. Obstet Gynecol. 2012;120 (1):113-122.

28. Abdel-Aziz Y, Metz DC, Howden CW. potassium-competitive acid blockers for the treatment of acid-related disorders. Alimentary Pharmacology \& Therapeutics. 2021 Apr;53(7):794809.

29. Fantasia HC. Low-dose aspirin for the prevention of preeclampsia. Nursing for women's health. 2018 Feb 1;22(1):8792.

30. Sharma V, Berkelhamer S, Lakshminrusimha S. Persistent pulmonary hypertension of the newborn. Maternal health, neonatology and perinatology. 2015 Dec;1(1):1-8.

31. Tablets C, Standard T. PrTEVA-CLOPIDOGREL.

32. Marsh CA, Cragan JD, Alverson CJ, Correa A. Case-control analysis of maternal prenatal analgesic use and cardiovascular malformations: Baltimore-Washington Infant Study

33. Werler MM, Mitchell AA, Hernandez-Diaz S, Honein MA. Use of over-the-counter medications during pregnancy. Am J Obstet Gynecol. 2005;193 (3 pt 1):771-777.
34. McClure CK, Katz KD, Patrick TE, Kelsey SF, Weiss HB (2011). The epidemiology of acute poisonings in women of reproductive age and during pregnancy, California, 2000-2004. Matern Child Health J 15(7):964-973

35. Saugstad OD. Acetaminophen and the Developing Brain: Reason for Concern?. Neonatology. 2020;117(2):245-248.

36. Allegaert K. How to translate neuro-cognitive and behavioural outcome data in animals exposed to paracetamol to the human perinatal setting?. Archives of Medical Science. 2020:1-3.

37. Ducros A, de Gaalon S, Roos C, Donnet A, Giraud P, GuéganMassardier E, Lantéri-Minet M, Lucas C, Mawet J, Moisset X, Valade D. Revised guidelines of the French headache society for the diagnosis and management of migraine in adults. Part 2: Pharmacological treatment. Revue Neurologique. 2021 Jul 30.

38. Abou-Atme YS, Melis M, Zawawi KH. Efficacy and safety of acetaminophen and caffeine for the management of acute dental pain: A systematic review. The Saudi dental journal. 2019 Oct $1 ; 31(4): 417-423$.

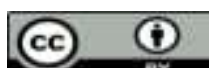

This work is licensed under Creative Commons Attribution 4.0 License

To Submit Your Article Click Here:

Submit Manuscript
Ready to submit your research? Choose Auctores and benefit from:

$>$ fast, convenient online submission

$>$ rigorous peer review by experienced research in your field

$>$ rapid publication on acceptance

$>$ authors retain copyrights

$>$ unique DOI for all articles

$>$ immediate, unrestricted online access

At Auctores, research is always in progress.

Learn more https://auctoresonline.org/journals/women-health-care-and-issues-

DOI: $10.31579 / 2642-9756 / 097$ 